\title{
Synthesis and up-conversion emission properties of Er-Yb co-doped double perovskite oxides
}

\section{$\mathrm{Er}-\mathrm{Yb}$ 共ドープダブルペロブスカイト型酸化物の合成とそのアップコンバージョン発光特性}

\author{
Mitomu ISHII \\ School of Science, Tokai University, 4-1-1 Kitakaname, Hiratsuka, Kanagawa, 259-1292 Japan \\ TEL: +81-463-58-1211 FAX: +81-463-58-9543 e-mail:mitomu.i@fuji.tokai-u.jp
}

Nobuhiro NAKAZATO, Kohei KASUYA, Koji TOMITA

Graduate School of Science, Tokai University, 4-1-1 Kitakaname, Hiratsuka, Kanagawa, 259-1292

Japan

TEL: +81-463-58-1211 FAX: +81-463-58-9543 e-mail: tomita@keyaki.cc.u-tokai.ac.jp

(Received 30 January, $2019 \quad$ Accepted 22 May, 2019)

Up-conversion phosphors emit light with shorter wavelength than that of excitation light. This phenomenon is caused by multi-photon excitation and energy transfer in $\mathrm{f}$ orbital of rare earth elements. In this study, $\mathrm{La}_{2} \mathrm{ZnTiO}_{6}$ and $\mathrm{La}_{2} \mathrm{MgTiO}_{6}$ doped with different amounts of $\mathrm{Er}$ and $\mathrm{Yb}$ was synthesized by the complex gelation method and the up-conversion (UPC) emission was investigated. In addition, we investigated the difference in optimum amount of $\mathrm{Er}$ and $\mathrm{Yb}$ for UPC emission due to host crystals. Main crystal phases of the synthesized samples were identified as $\mathrm{La}_{2} \mathrm{ZnTiO}_{6}$ and $\mathrm{La}_{2} \mathrm{MgTiO}_{6}$ respectively by X-ray diffraction. Up-conversion emissions were measured using a spectrometer with a multi-channel photo detector and a diode laser emitting excitation light at $980 \mathrm{~nm}$. The optimum amount of $\mathrm{Er}$ and $\mathrm{Yb}$ in $(\mathrm{La}, \mathrm{Er}, \mathrm{Yb})_{2} \mathrm{ZnTiO}_{6}$ for the up-conversion emission were $1 \mathrm{~mol} \%$ and $5 \mathrm{~mol} \%$, respectively. On the other hand, the optimum amount of $\mathrm{Er}$ and $\mathrm{Yb}$ in ( $\mathrm{La}, \mathrm{Er}, \mathrm{Yb})_{2} \mathrm{MgTiO}_{6}$ were $2 \mathrm{~mol} \%$ and $2 \mathrm{~mol} \%$, respectively. The optimized sample showed strong green and red emissions. As the result, it was shown that the double perovskite type oxide doped with Er and $\mathrm{Yb}$ showed UPC luminescence, and the optimum doping amount of Er and $\mathrm{Yb}$ depended on the host crystal.

Keywords : Up-conversion phosphor, $\mathrm{La}_{2} \mathrm{ZnTiO}_{6}, \mathrm{La}_{2} \mathrm{MgTiO}_{6}$, Parallel synthesis, Rare earth

\section{INTRODUCTION}

アップコンバージョン(up-conversion : UPC)蛍光体とは、 長波長の光を用いて多光子・多段階で励起し、短波長の 光に変換する光機能性材料である。UPC 蛍光体は、太陽 電池や 3D ボリュームディスプレイ、生体イメージング 等、光機能性材料として様々な分野での応用が期待され ている。1-3

SAS Award was given to this paper presented as Poster Presentation at the 2018 SAS Symposium.
希土類イオンを利用するアップコンバージョン蛍光体 では、母体結晶となる酸化物やフッ化物等に、光増感剂 と発光中心の 2 種の希土類イオンをドープする。 $\mathrm{Yb}^{3+}$ は 4f 軌道のエネルギー準位が 2 つかないため、980nm 付 近の光のみを吸収し、光増感剤として利用される。ここ へ $\mathrm{Er}^{3+} \mathrm{Tm}^{3+} 、 \mathrm{Ho}^{3+}$ といった他の希土類イオンを発光中 心として共ドープすることにより、Ybが吸収したエネル ギーがこれらのイオンへ移動し、多段階(多光子)励起が 起こり、UPC 発光を示す。 ${ }^{4}$ Figure 1 に Yb と Er による 近赤外励起-可視発光のプロセスを示す。5-6 
Figure 2 に $\mathrm{Er}$ と $\mathrm{Yb}$ を共ドープした $\mathrm{La}_{2} \mathrm{MTiO}_{6}(\mathrm{M}=\mathrm{Zn}$, $\mathrm{Mg})$ は、強い緑色 UPC 発光を示すことが報告されている。 そこで本研究では、錯体ゲル化法により $(\mathrm{La}, \mathrm{Er}$, $\mathrm{Yb})_{2} \mathrm{MTiO}_{6}(\mathrm{M}=\mathrm{Zn}, \mathrm{Mg})$ を合成し、ドープ量を変化させる ことによる発光特性の評価を行った。
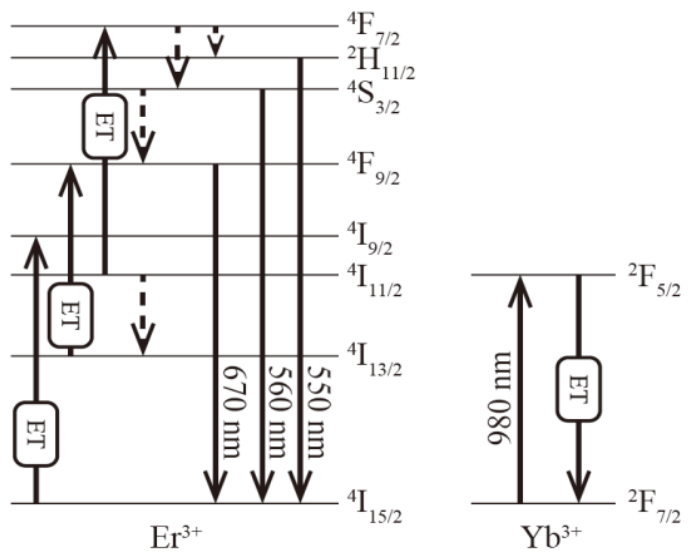

Fig. 1. Energy diagram to explain the emission $f$ UPC luminescence at the photon energies of $1.85 \mathrm{eV}(670 \mathrm{~nm})$, $2.21 \mathrm{eV}(560 \mathrm{~nm})$ and $2.25 \mathrm{eV}(550 \mathrm{~nm})$ in double perovskite oxide co-doped with $\mathrm{Er}$ and $\mathrm{Yb}$ after excitation at the photon energy of $1.26 \mathrm{eV}(\lambda=980 \mathrm{~nm})$. ET and dashed arrows correspond to energy transfer and nonradiative transitions, respectively.

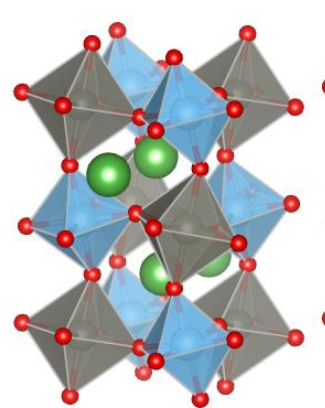

(a)

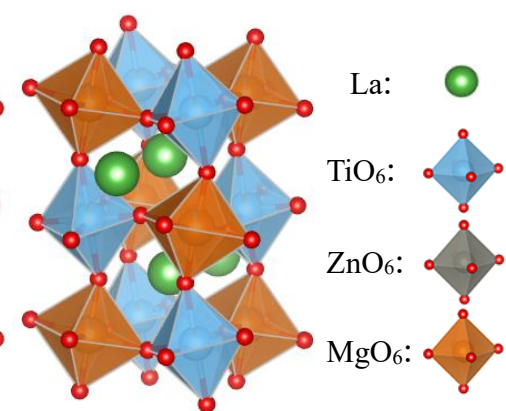

(b)
Fig. 2. Crystal structure of the $\mathrm{La}_{2} \mathrm{ZnTiO}_{6}$ (a) and $\mathrm{La}_{2} \mathrm{MgTiO}_{6}$ (b).

\section{EXPERIMENTAL}

$\mathrm{Zn}\left(\mathrm{NO}_{3}\right)_{2} \cdot 6 \mathrm{H}_{2} \mathrm{O}$ (日本イットリウム株式会社 純度 99.0\%)を蒸留水に溶解し $\mathrm{Zn}\left(\mathrm{NO}_{3}\right)_{2}$ aq. を作製した。 $\mathrm{MgCl}_{2}$ ・ $6 \mathrm{H}_{2} \mathrm{O}$ (和光純薬工業株式会社 純度 $99.9 \%$ ) を蒸留水に溶 解し、 $\mathrm{MgCl}_{2}$ aq.を作製した。クエン酸(和光純薬工業株式 会社 純度 $98.0 \%$ )を蒸留水に溶解しクエン酸水溶液を作 製した。 $\mathrm{La}_{2} \mathrm{O}_{3}$ (日本イットリウム株式会社 純度 99.9\%)、
$\mathrm{Er}_{2} \mathrm{O}_{3}$ (日本イットリウム株式会社 純度 $99.9 \%$ )、 $\mathrm{Yb}_{2} \mathrm{O}_{3}$ (日 本イットリウム株式会社 純度 99.9\%) をそれぞれ $\mathrm{HNO}_{3}$ (和光純薬工業株式会社 純度 60 61\%)に溶解し、加 熱により過剰な $\mathrm{HNO}_{3}$ を除去した後、蒸留水を加えてそ れぞれの硝酸塩水溶液を作製した。またクエン酸チタン 錯体水溶液 ${ }^{7}$ を作製した。

作製した原料水溶液を用い、錯体ゲル化法によって目 的サンプルである、 $(\mathrm{La}, \mathrm{Er}, \mathrm{Yb})_{2} \mathrm{MTiO}_{6}(\mathrm{M}=\mathrm{Zn}, \mathrm{Mg})$ を作製 した。試験管に、La と $\mathrm{Er}$ と $\mathrm{Yb}$ の合計が $1 \mathrm{mmol} 、 \mathrm{Zn}$ ま たは $\mathrm{Mg}$ を $0.5 \mathrm{mmol} 、 \mathrm{Ti}$ を $0.5 \mathrm{mmol}$ となるように各水溶 液を加えた。 $\mathrm{La}$ と $\mathrm{Er}$ と $\mathrm{Yb}$ の合計に対し、 $\mathrm{Er}$ のドープ 量を $1 、 2 、 5 、 10 \mathrm{~mol} \%$ とし $\mathrm{Yb}$ のドープ量を $0 、 1 、 2 、$ 5、 $10 \mathrm{~mol} \%$ とした。ゲル化剂としてクエン酸水溶液を $10 \mathrm{mmol}$ 加え、攪拌した。この水溶液を $120^{\circ} \mathrm{C}$ で加熱濃縮 させた後、さらに $450^{\circ} \mathrm{C} て ゙ 5$ 時間焼成し、メノウ乳鉢を 用いて粉砕した。それぞれの試料をるつぼに移し、電気 炉を用いて $1200^{\circ} \mathrm{C} 5$ 時間、大気雰囲気下で焼成した。

合成したサンプルを、X 線回折(XRD、Bruker AXS, D8 ADVANCE)を用いた構造評価、赤外半導体レーザー $(980$ nm, Thorlabs L980P300J)を励起光としてマルチチャンネ ル分光器 (大塚電子, MCPD-7700:311C)による赤外励起可視発光スペクトル測定を行った。

\section{RESULTS AND DISCUSSION}

Figure 3 に、 $\mathrm{La}_{2} \mathrm{ZnTiO}_{6}$ を母体とする UPC 蛍光体の XRD パターンを示す。これらは $\mathrm{Er} の$ の゙ープ量が 1, 2, 5, 10mol\%の 4 種のサンプルそれぞれにおいて最も強い発 光強度を示した $\mathrm{Yb}$ ドープ量のサンプルである。いずれ のサンプルにおいても、計算值（ $\mathrm{LaZn}_{0.5} \mathrm{Ti}_{0.5} \mathrm{O}_{3}$, ICSD\#172755）の回折パターンとピーク一致しているこ とから、目的サンプルが単相で合成できたといえる。

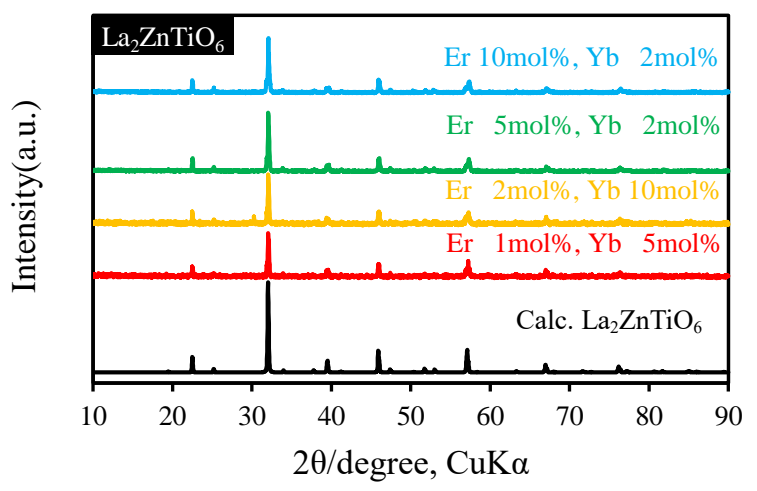

Fig. 3. Experimental and calculated XRD patterns of $\mathrm{La}_{2} \mathrm{ZnTiO}_{6}$ co-doped with $\mathrm{Er}$ and $\mathrm{Yb}$. 
Figure 4 に、最も強い発光を示した (La0.94Er0.01 $\left.\mathrm{Yb}_{0.05}\right)_{2} \mathrm{ZnTiO}_{6}$ の発光スペクトルを示す。510〜 $580 \mathrm{~nm}$ の緑色領域及び 640〜 680 nm の赤色領域の 2 箇所 にピークが確認された。緑色領域のピークは $528 \mathrm{~nm}$ と $544 \mathrm{~nm}$ とに二股に分かれている。これらはそれぞれ ${ }^{2} \mathrm{H}_{11 / 2}$ と ${ }^{4} \mathrm{~S}_{3 / 2}$ から基底状態の ${ }^{4} \mathrm{I}_{15 / 2}$ への遷移に基づく発光に帰 属できる。赤色領域の発光は ${ }^{4} \mathrm{~F}_{9 / 2}$ から ${ }^{4} \mathrm{I}_{15 / 2}$ への遷移に帰 属できる。以上より、励起された $\mathrm{Yb}^{3+}$ のエネルギー移動 により、 $\mathrm{Er}^{3+}$ が多光子励起-可視発光する際に複数のプロ セスが同時に起こっていることが確認できた。

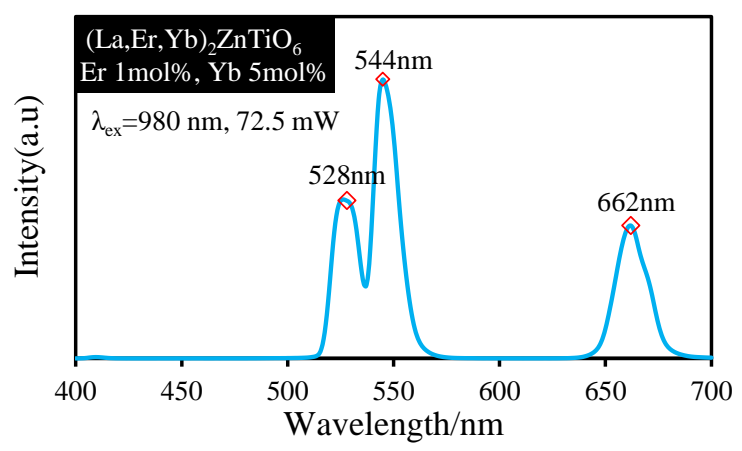

Fig. 4. Emission spectrum of $\mathrm{La}_{2} \mathrm{ZnTiO}_{6}$ co-doped with $1 \%$ of Er and 5\% of Yb.

Figure 5 に、作製したサンプルの発光スペクトルにお ける 500〜 600nm の積分值をまとめたものを示す。最も 発光強度が強いサンプルのドープ量は、Er $1 \mathrm{~mol} \%$ と $\mathrm{Yb}$ $5 \mathrm{~mol} \%$ \%゙あった。カラーマッピングの色はこのサンプル の発光積分強度を $100 \%$ とする相対的な強度を色で示し た。ドープ量と発光強度の傾向として、Erのドープ量が 増加すると、発光強度が著しく低下寸ることが確認され

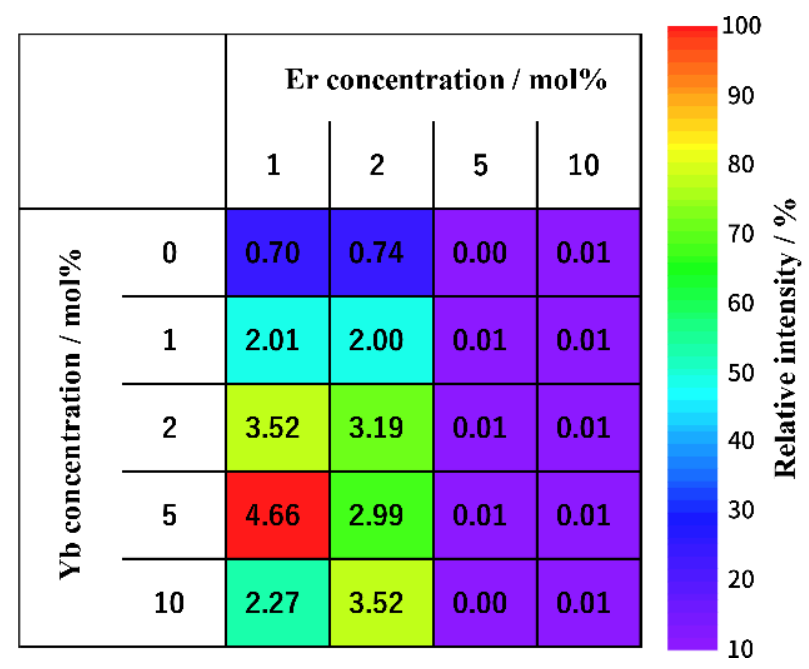

Fig. 5. Intensity color mapping of green UPC emission of $\mathrm{La}_{2} \mathrm{ZnTiO}_{6}$ co-doped with different concentration of Er and $\mathrm{Yb}$ under 980nm excitation.
た。一般に、準位の多い発光中心のドープ量が増加する と交差緩和によって発光強度が低下寸ることが知られて いるが、 ${ }^{8}$ 本研究によって用いたダブルペロブスカイトの ような複合酸化物を母体とする UPC 蛍光体においても 同様の効果が現れることが明らかとなった。また、Ybの ドープ量について注目すると、励起波長の $980 \mathrm{~nm}$ の吸 収をより多く行うために、Ybが濃度消光を起こさない範 囲で Erに対して Yb を多くすることが望ましい。

Figure 6 に、 $\mathrm{La}_{2} \mathrm{MgTiO}_{6}$ を母体とする UPC 蛍光体の XRD パターンを示す。Figure 3 と同様に Er のドープ量 が 1, 2, 5, 10mol\%の 4 種のサンプルにおいて最も強い発 光強度を示した $\mathrm{Yb}$ のドープ量のサンプルを載せた。い ずれのサンプルにおいても、回折角度が計算值 $\left(\mathrm{LaMg}_{0.5} \mathrm{Ti}_{0.5} \mathrm{O}_{3}, \mathrm{ICSD}_{4} 95992\right)$ の回折パターンとピーク が一致していることから、 $\mathrm{La}_{2} \mathrm{MgTiO}_{6}$ を母体とした UPC 蛍光体についても、目的のサンプルが単相で合成できた といえる。

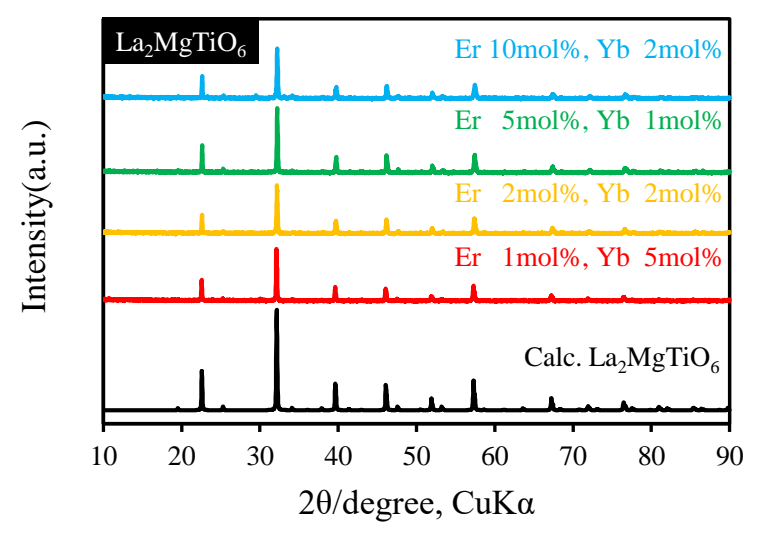

Fig. 6. Experimental and calculated XRD patterns of $\mathrm{La}_{2} \mathrm{MgTiO}_{6}$ co-doped with $\mathrm{Er}$ and $\mathrm{Yb}$.

Figure 7 に最も強い可視発光を示した $(\mathrm{La}, \mathrm{Er}$, $\mathrm{Yb})_{2} \mathrm{MgTiO}_{6}$ のスペクトルを示す。スペクトル形状は(La, $\mathrm{Er}, \mathrm{Yb})_{2} \mathrm{ZnTiO}_{6}$ と同様であり、ピーク位置についても \pm 2 $\mathrm{nm}$ の範囲で非常に近い波長の位置に出ている。従って、 $\mathrm{Er}, \mathrm{Yb}$ をドープしたことによる多光子励起-可視発光に差 は見られないことが確認された。

Figure 8 に、合成した $(\mathrm{La}, \mathrm{Er}, \mathrm{Yb})_{2} \mathrm{MgTiO}_{6}$ の発光スペク トルの 500〜 600nm の積分值とカラーマッピングを示す。 この内、最も強い発光強度を示したサンプルは Er 2mol\%, $\mathrm{Yb} 2 \mathrm{~mol} \%$ \%゙った。(La, Er, $\mathrm{Yb})_{2} \mathrm{MgTiO}_{6}$ においても、 $\mathrm{Er}$ のドープ量が $5 \mathrm{~mol} \%$ 以上のサンプルは濃度消光の影響 により、発光強度は Er $2 \mathrm{~mol} \%$ 以下のサンプルよりも低い 值であった。

$\mathrm{Zn}$ 母体と $\mathrm{Mg}$ 母体それぞれの最も強い発光を示したサ 
ンプル同士で比較すると、 $\mathrm{Zn}$ 母体のサンプルの積分值を $100 \%$ とすると $\mathrm{Mg}$ 母体のサンプルは 101\%であり、ほぼ 同程度であった。一方、最適なドープ量は、Zn 母体では $\mathrm{Er} 1 \%, \mathrm{Yb} 5 \% 、 \mathrm{Mg}$ 母体では Er 2\%,Yb 2\%と異なる值であ った。これは、母体結晶のわずかな歪の違いにより、Er と $\mathrm{Yb}$ 周囲の環境が変化し、その影響で f-f 電気双極子遷 移の確率が変化し、 Er や Yb の励起や発光の確率および、 Er 同士での交差緩和の確率に違いが生じることで、この ような差が発生したと考えられる。

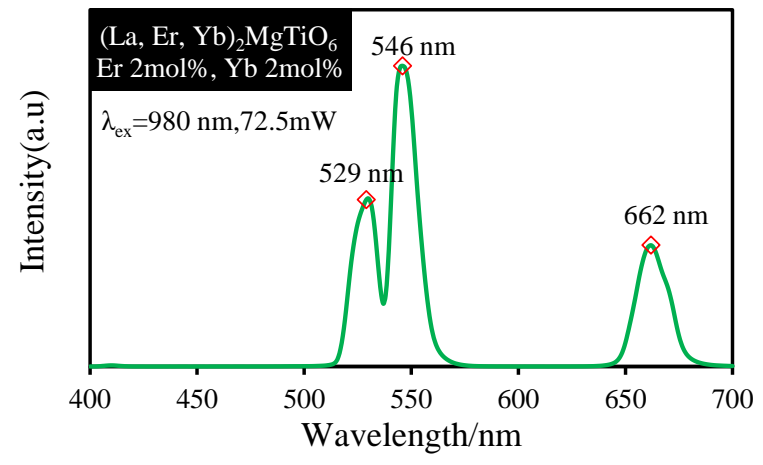

Fig. 7. Emission spectrum of $\mathrm{La}_{2} \mathrm{MgTiO}_{6}$ co-doped with $2 \%$ of Er and $2 \%$ of $\mathrm{Yb}$.

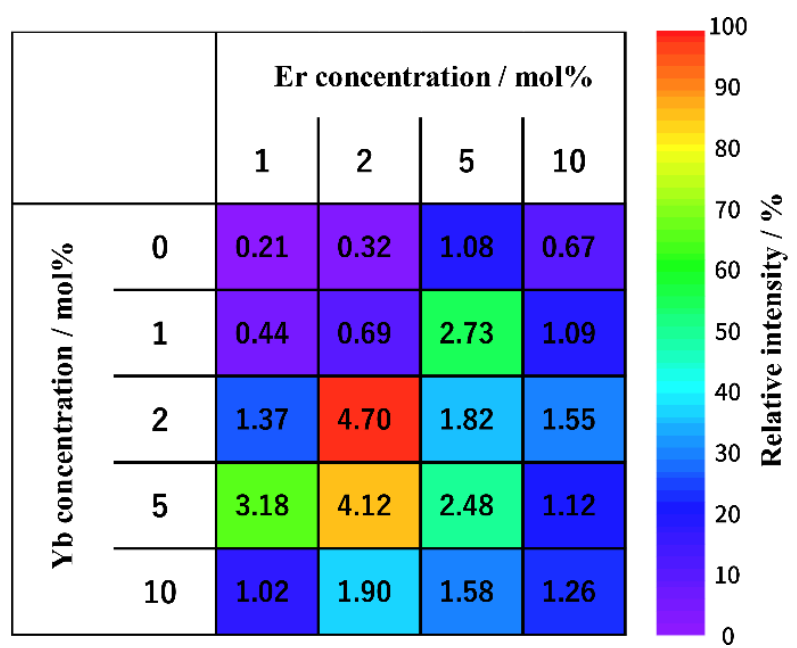

Fig. 8. Intensity color mapping of green UPC emission of $\mathrm{La}_{2} \mathrm{MgTiO}_{6}$ co-doped with different concentration of Er and $\mathrm{Yb}$ under 980nm excitation.

\section{CONCLUSION}

ダブルペロブスカイト酸化物である、 $\mathrm{La}_{2} \mathrm{MTiO}_{6}(\mathrm{M}=\mathrm{Zn}$, $\mathrm{Mg})$ を母体結晶とする $\mathrm{Er}, \mathrm{Yb}$ 共ドープ UPC 蛍光体を錯体 ゲル法により合成し、その発光特性について評価を行っ た。(La, Er, Yb) ${ }_{2} \mathrm{ZnTiO}_{6}$ では、ドープ量 $\mathrm{Er} 1 \mathrm{~mol} \%, \mathrm{Yb} 5 \mathrm{~mol} \%$ において最も高い UPC 発光を示した。一方で、( $\mathrm{La}, \mathrm{Er}$, $\mathrm{Yb})_{2} \mathrm{MgTiO}_{6}$ では、ドープ量 $\mathrm{Er} 2 \mathrm{~mol} \%, \mathrm{Yb} 2 \mathrm{~mol} \%$ におい て最も高い UPC 発光を示した。XRD より、合成したサ ンプルは $\mathrm{La}_{2} \mathrm{ZnTiO}_{6}$ と $\mathrm{La}_{2} \mathrm{MgTiO}_{6}$ の単相で得られること を確認した。以上より、UPC 蛍光を示すダブルペロブス カイト型酸化物において、最適な $\mathrm{Er}, \mathrm{Yb}$ ドープ量は母体 結晶によって異なることが示された。

\section{ACKNOWLEDGEMENTS}

本研究は文部科学省理数学生応援プロジェクト「サイエ ンス・マイスター育成プログラム」の一環として行われた。

\section{REFERENCES}

${ }^{1}$ F. Wang, Y. Han, C. S. Lim, Y. Lu, J. Wang, J. Xu, H. Chen, C. Zhang, M. Hong and X. Liu, Nature, 463, pp. 1061-1065 (2010).

${ }^{2}$ W. Yin, L. Zhou, Z. Gu, G. Tian, S. Jin, L. Yan, X. Liu, G. Xing, W. Ren, F. Liu, Z. Pan and Y. Zhao, J. Mater. Chem., 22, pp. 6974-6981 (2012).

3 J. M. Meruga, A. Baride, W. Cross, J. J. Kellar and P. S. May, J. Mater. Chem. C, 2, pp. 2221-2227 (2014).

${ }^{4}$ S. Huang, X. Zhang, L. Wang, L. Bai, J. Xu, C. Li and P. Yang, Dalton Trans., 41, pp. 5634-5642 (2012).

5 Koji Tomita, Optical Alliance, 25(10),.pp. 13-16, (2014-10) (in Japanese).

${ }^{6}$ G. H. Dieke and H. M. Crosswhite, Appl. Optics, 2, pp. 675-686 (1963).

7 M. Kakihana, K. Tomita, V. Petrykin, M. Tada, S. Sasaki, Y. Nakamura, Inorg. Chem., 43, pp.45464548 (2004).

${ }^{8}$ Keikoutaidougakukai, Phosphor Handbook, (Ohmsha, 1987) (in Japanese). 